IRA-International Journal of Management \& Social Sciences

ISSN 2455-2267; Vol.10, Issue 01 (January 2018)

Pg. no. 16-26

Institute of Research Advances

http://research-advances.org/index.php/RAJMSS

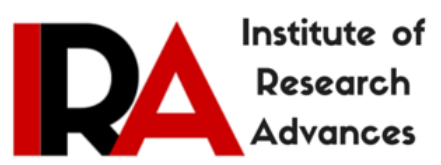

\title{
Educating the Academe- How Academic Homogeneity Stifles Racial Diversity
}

\author{
Zachary W. Taylor \\ Research Assistant, The University of Texas at Austin, Austin, TX, 78712, United States .
}

Type of Review: Peer Reviewed.

DOI: http://dx.doi.org/10.21013/jmss.v10.n1.p2

How to cite this paper:
Taylor, W. Z. (2018). Educating the Academe- How Academic Homogeneity Stifles Racial Diversity.
IRA-International Journal of Management \& Social Sciences (ISSN 2455-2267), 10(1), 16-26.
doi:http://dx.doi.org/10.21013/jmss.v10.n1.p2

(C) Institute of Research Advances.

(cc) BY-NC

This work is licensed under a Creative Commons Attribution-Non Commercial 4.0 International License subject to proper citation to the publication source of the work.

Disclaimer: The scholarly papers as reviewed and published by the Institute of Research Advances (IRA) are the views and opinions of their respective authors and are not the views or opinions of the IRA. The IRA disclaims of any harm or loss caused due to the published content to any party.

Institute of Research Advances is an institutional publisher member of Publishers Inter Linking Association Inc. (PILA-CrossRef), USA. The institute is an institutional signatory to the Budapest Open Access Initiative, Hungary advocating the open access of scientific and scholarly knowledge. The Institute is a registered content provider under Open Access Initiative Protocol for Metadata Harvesting (OAI-PMH).

The journal is indexed \& included in WorldCat Discovery Service (USA), CrossRef Metadata Search (USA), WorldCat (USA), OCLC (USA), Open J-Gate (India), EZB (Germany) Scilit (Switzerland), Airiti (China), Bielefeld Academic Search Engine (BASE) of Bielefeld University, Germany, PKP Index of Simon Fraser University, Canada. 


\begin{abstract}
Although there is a wealth of research to support the notion that the American professoriate is not as racially and ethnically diverse as it could and should be, very little research has focused on the particular academic backgrounds of Higher Education faculty members in American universities. The purpose of the study is to examine the academic backgrounds of higher education administration faculty members (all ranks of professors, lecturers, and clinical staff; $n=119)$ employed at America's top 10 universities for Higher Education Administration according to the 2016 list compiled by U.S. News \& World Report. Findings suggest that Liberal Arts (62\% of Bachelor's degrees) produce the most faculty members, while Education (5\%) produces nearly the fewest amounts. Findings also suggest that Psychology, Sociology, Economics, and English are the most common undergraduate academic fields producing higher education faculty members, yet these are academic pathways that Black/African-American and Hispanic/Latino undergraduates rarely take, possibly contributing to the lack of racial and ethnic diversity in the higher education professoriate and other related fields. Implications for policy, practice, and future research are addressed.
\end{abstract}

Keywords: higher education, faculty, diversity, policy, equity

\title{
Introduction
}

University of Pennsylvania Professor of Higher Education Marybeth Gasman's September $26^{\text {th }}, 2016$ opinion in The Washington Post made headlines in the higher education community - and the academic community in general-for her seemingly tongue-in-cheek response to the question about the lack of faculty of color at many majority institutions, namely elite institutions of higher education (IHEs). She plainly said, "The reason we don't have more faculty of color among college faculty is what we don't want them. We simply don't want them."

Gasman's "We don't want them" sentiment resonated throughout the academe and found a voice in many popular news outlets, but Gasman's undergirding — and perhaps more salient — claim for this lack of faculty of color was a mere footnote and begs further examination: she spoke of "the faculty pipeline." Of this "faculty pipeline," Gasman remarked:

It is accurate that there fewer people of color in some disciplines such as engineering or physics. However, there are great numbers of Ph.D.'s of color in the humanities and education and we still don't have great diversity on these faculties.

It should be noted that Gasman's remarks were meant to encompass a conversation of elite institutions hiring people of color in all fields of study, not merely her own field of Higher Education, but these three lines spoke volumes about the fundamental assumptions of the "faculty pipeline" as it pertains to the professoriate at large.

First, Gasman's notion of the "faculty pipeline" assumes that there are fewer people of color in disciplines such as engineering and physics (science, technology, engineering, and math or STEM fields). This is true: a wealth of research supports the position that minorities (Hurtado, Newman, Tran, \& Chang, 2010; Museus, Palmer, Davis, \& Maramba, 2011; Pentyala, Dilger,\&Rebecchi, 2016)—especially African-American women (Ceglie, 2011)—do not graduate from STEM fields nearly as frequently as their White peers. Furthermore, only $45 \%$ of all Mathematics/Computer Science graduate school enrollees and 38\% of all Engineering graduate school enrollees are non-White (Okahana, Feaster, \& Allum, 2016).

Second, Gasman's "faculty pipeline" assumes that there are "great numbers of Ph.D.'s of color in the humanities and education." This statement is misleading. According to the Council of Graduate Schools, underrepresented minority groups composed only $22.5 \%$ of all first-time graduate students in all fields in Fall 2015 (Okahana, Feaster, \& Allum, 2016). Therefore, only one in five faculty candidates, conceivably, would be a person of color across all academic disciplines. And the discrepancies continue. At the graduate level, Hispanic/Latino students are more likely to enroll in Public Administration (14.6\%) and Social/Behavioral Sciences (12.2\%) programs than Arts and Humanities (10.0\%) or Education (11.1\%) programs; Black/African-American students are more likely to enroll in Public Administration (17.9\%), Social/Behavioral Sciences (12.9\%), and Business (12.5\%) programs than Arts and Humanities (5.9\%) or Education (12.4\%) programs; Asian students are more likely to enroll in Mathematics/Computer Science (15.1\%) and Engineering (14.0\%) programs than Arts and Humanities (4.3\%) or Education (3.4\%) programs (Okahana, Feaster, \& Allum, 2016). Collectively, all racial and ethnic minorities total only $31.3 \%$ of Arts and Humanities graduate students and 37.3\% of all Education graduate students. Diminishing 
these numbers still is the recent research that found only $48 \%$ of Hispanic/Latino doctoral students and $40 \%$ of Black/African-American doctoral students completed their degree within seven years, compared to $55 \%$ of their White peers (Sowell, Allum, \& Okahana, 2015).

To recap: roughly one-third of all graduate students are Hispanic/Latino and Black/African-American, and of this one-third, fewer than one half graduate with their doctoral degree. Surely, these statistics do not constitute a "great numbers of Ph.D.'s of color in the humanities and education" conclusion. As a result, "great numbers" must be a misnomer meant to mean "great numbers" in relation to STEM fields. Compounding the misleading nature of this misnomer is the fact that it appeared in The Washington Post with its greater and more diverse readership as opposed to The Journal of Higher Education's more distinct audience who are better able to discern the postsecondary idiosyncrasies implied in Gasman's statement.

Third, Gasman's "great numbers" assumes the false metonymy of "people of color" defined as Hispanic/Latino or Black/African-Americans: the representation of American Indian/Alaska Native students and Native Hawaiian/Pacific Islander students in Arts and Humanities and Education is much lesser than Hispanic/Latino or Black/African-American students. In fact, American Indian/Alaska Native students only comprised $0.5 \%$ of all Arts and Humanities and $0.5 \%$ of all Education graduate students; Native Hawaiian/Pacific Islander students only comprised $0.2 \%$ of all Arts and Humanities and $0.2 \%$ of all Education graduate students in Fall 2015 (Okahana, Feaster, \& Allum, 2016). As previously articulated, 0.2\% and 0.5\% of students-in any academic discipline - simply cannot adequately contribute to "great numbers of Ph.D.'s." As a result, this false metonymy was perpetuated in the popular media, further subjugating American Indian/Alaska Native students and Native Hawaiian/Pacific Islander students into the category of the forgotten.

Fourth, Gasman draws connecting lines running from "great numbers of Ph.D.'s of color in the humanities and education" to not having "great diversity on these faculties." This is true but problematic. A plethora of higher education research laments the lack of faculty of color at working in IHEs (Abdul-Raheem, 2016; Edwards, 2015; Finkelstein, Conley,\& Schuster, 2016), however, the collocation of ethnicity and race to the general notion of "diversity" marginalizes other forms of diversity in the academe, especially when addressing a general audience (The Washington Post) as Gasman did. Diversity is an incredibly complex term and can be applied to a plethora of social groups. Gender, sexual orientation, age, and professional background diversity all contributes to a truly multicultural education expressed by many elite IHEs as essential to the college experience. However, more pertinent to Gasman's remarks is another form of diversity rarely researched in the field of Higher Education: academic diversity.

In postsecondary circles, it is common knowledge that the Bachelor's degree in Higher Education does not exist. Of course, however, the general public may not have this knowledge and therefore do not think to beg the question: if the BA or BS in Higher Education does not exist, what undergraduate experience predicts a career in the Higher Education academe? In many cases, aBS in Biology attends graduate school in Biology or becomes a Biologist in some shape, manner, or form. Likewise, the BBA in Accounting attends graduate school in Accounting or becomes an Accountant. But does the Bachelor of Arts in Italian attend graduate school in Anthropology and then a doctoral program in Sociology to pursue tenure as a Professor of Higher Education? And does the person of color take this alternative pathway toward the Higher Education professoriate? What does the academic background does the Higher Education academe have?

In other words, where do the Marybeth Gasmans of the world come from?

And could the undergraduate education of higher education faculty members inform the lack of racial and ethnic diversity in the professoriate in general? Of course, the term "diversity" can be defined in many ways, yet higher education research has not focused on the academic diversity of the Higher Education professoriate and whether or not such diversity can inform policy and practice related to the recruitment, retention, tenure processes, and career fulfilment of people of color in faculty positions across all fields of study. Here, the mirror needs to be turned inward, onto the field of Higher Education, a field where it is entirely possible for an Italian major to study Anthropology, then Sociology, and then become a Professor Higher Education.

Currently, no scholarly research exists that examines the academic undergraduate backgrounds and first graduate experienced of Higher Education faculty members, constituting a gap in the literature that may help inform 
the lack of racial and ethnic diversity on postsecondary faculties. Therefore, the purpose of this study was to perform a semantic analysis of the pre-doctoral academic backgrounds of all ranks of professors, lecturers, and clinical faculty of higher education $(\mathrm{n}=119)$ in U.S. News \& World Report's 2016 rankings of best "Higher Education Administration" programs in the United States (U.S. News \& World Report, 2016). Ideally, this study will provide insight for academic and career counselors to guide underrepresented racial and ethnic minority undergraduates toward pre-graduate and graduate school pathways to higher education leadership, especially careers in faculty positions at elite IHEs.

\section{Methodology}

To conduct this study, I first needed to refine the data collection: there are hundreds of higher education faculties across the country. Therefore, using Gasman's "We don't want them" synecdoche pronoun "We" to mean elite IHEs, I decided on focus on the ten most elite Higher Education Administration programs and their faculty as detailed by U.S. News \& World Report in 2016. In order, these ten schools were the University of Michigan-Ann Arbor, Michigan State University, the University of California-Los Angeles, the University of Pennsylvania, the University of Southern California, the University of Georgia, Pennsylvania State University-University Park, Vanderbilt University, Indiana University-Bloomington, and the University of Maryland-College Park. Collectively, these ten elite IHEs employ 119 Higher Education Administration faculty members (HEAFMs), ranging from full professors to adjunct lecturers to clinical staff members.

Articulating the academic backgrounds of the higher education professoriate was as simple as an institutional search for each faculty member's curriculum vitae (CV) on each institution's ".edu" website. If the CV or education information was not posted on the faculty member's institutional ".edu" webpage, I simply emailed each faculty member, asking for their degree type and field of study using the email address listed on their profile page. I began the data collection process in the first week of November 2016, and by December $10^{\text {th }}$, 2016, I had gathered complete academic background knowledge of 114 of the 119 HEAFMs across ten elite IHEs, and the type and field of at least one degree for all 119 faculty members.

As each faculty member's background was discovered, I extracted the information and uploaded it into a database with five categories: Name, Institution, Bachelor's degree or equivalent, Master's degree or equivalent, and Doctorate degree or equivalent. This allowed for quick sorting as well as alphabetization to determine the type and frequency of each Bachelor's, Master's, and Doctoral degree. In the cases where a faculty member held two degrees of any type, I simply entered the title of the first degree earned chronologically, followed by a comma and the title of the second degree earned chronologically. All Bachelor's and Master's degrees were included in the data and findings: Doctoral degree data was gathered for consideration for future research.

After the data was entered, I needed to code each degree as a specific type to standardize my findings (e.g., a BS in Civil Engineering Management was coded as an "Engineering" degree). Given the expansive, mutable nature of undergraduate studies both now and in prior decades, I used the thirteen colleges and schools and 170 degree types awarded by the University of Texas at Austin (2016) as a method of standardization. This approach organized my findings by likely degree-granting college and major type, given the diversity of academic backgrounds held by the higher education professoriate. Certain degrees, such as a dual major in Music and Psychology, were coded as separate degrees in two fields. Other idiosyncratic degrees were organized into the field I thought best encompassed the content of that particular major (e.g. Bachelor's degree in Political Economy of Industrial Societies was coded as a "Political Communication" degree and was coded as a "Communications" degree).

Master's degrees were organized in a similar fashion, only I organized all Master's degrees containing "Higher Education," "Continuing Education," "College Student," "Student Affairs," and "Student Personnel" as a "Higher Education" Master's degree, as these degrees were extremely plentiful and extremely differentiated in title within the single, core discipline of Higher Education. Furthermore, I deferred to UT-Austin's translation if a Master's degree seemingly encompassed multiple disciplines (e.g. an MS in Human Development and Relations is similar to "Human Development" and was coded as a "Natural Sciences" degree).

\section{Limitations}

The chief limitations of this study are the sample size and self-reporting of degree type and field of study. 
Of the thousands of HEAFMs in IHEs across the country, 119 seems a small sample size. Furthermore, I extracted the data for this study from self-reported CVs: it is entirely possible that a faculty member listed their Bachelor's degree as being in "Latin" where the true title of the degree was "Foreign Language Studies" or a similar error in transcription. However, given Gasman's call for elite IHE's to be more equitable in terms of hiring people of color to faculty positions, I felt that the top ten Higher Education Administration programs as articulated by U.S. News \& World Report was a fantastic starting point. An expansion of the sample size or more rigorous auditing of degree type and field of study represents possibilities for future studies and research.

\section{Findings} below.

A table listing the Bachelor's degrees of 119 Higher Education Administration faculty members is listed 
Table 1

Bachelor's Degrees Held by Higher Education Administration Faculty Members $(n=119)$

College* $\quad$ \# of Degrees $\quad$ Degree, (\#) Earned

\begin{tabular}{|c|c|c|}
\hline Business & 6 & $\begin{array}{l}\text { Business (1), Business Administration and Finance (1), Business and Marketing Management (1), Business } \\
\text { Economics (2), Industrial Technology (1) }\end{array}$ \\
\hline Communication & 17 & $\begin{array}{l}\text { Communication Arts (1), Communications (2), Human Resources Management (1), Journalism (2), Political } \\
\text { Economy of Industrial Societies (1), Political Science (8), Public Administration (1), Speech Communications (1) }\end{array}$ \\
\hline Education & 7 & $\begin{array}{l}\text { Education (2), Educational Research (1), Elementary Education (1), Exercise and Health Science (1), Health and } \\
\text { Physical Education (1), Middle Grades Education (1) }\end{array}$ \\
\hline Engineering & 4 & Ceramic Engineering (1), Civil Engineering Management (1), Electrical Engineering (2) \\
\hline Fine Arts & 5 & Art History (2), Music (3) \\
\hline
\end{tabular}

American Government (1), Anthropology (2), Criminology (1), Critical Theory and Social Justice (1), Economics (9), English (9), English and American Literature (1), English and Comparative Literature (1), English Language and Literature (1), English Literature (3), French (1), French Literature (1), History (8), International Relations (3), International Political Economy (1), Liberal Arts (1), Philosophy (3), Psychology (15), Romance Languages (1), Liberal Arts 81 Religion (2), Sociology (11) Social Studies (1), Social Relations (1), Spanish (2), Women's Studies (1)

Natural Sciences 10

Human Biology (2), Chemistry (2), Consumer and Family Sciences (1), Family Studies (1), Mathematics (2), Medical Microbiology (1), Physics (1)

Total 130

3 Most Common: Psychology (15), Sociology (11), Economics, English (9)

equivalent colleges and disciplines of Architecture, Geosciences, Nursing, Pharmacy, or Social Work. 
Overwhelmingly, HEAFMs receive their Bachelor's degrees in Liberal Arts fields (81 total degrees), as Psychology (15 degrees), Sociology (11), Economics (9), and English (9) were the most common degrees. This represents $62 \%$ of all Bachelor's degrees earned by HEAFMs. Communication degrees are also well represented (17 degrees), followed by degrees in Natural Sciences (10 degrees). It is clear that the disciplines of Architecture, Geosciences, Nursing, Pharmacy, and Social Work do not produce HEAFMs in high numbers, as the 119 faculty members featured in this study hold zero degrees in these five fields.

A number of idiosyncrasies exist in the data. First, the National Center for Education Statistics (2016) found that up until 2014, postsecondary institutions conferred the most Bachelor's degrees in the fields of Business, Health Professions, and Social Sciences and History. However, Business and Health Professions were two of the least represented fields for HEAFMs. Additionally, the data clearly show that Engineering and the Fine Arts are fields that do not produce a high number of HEAFMs (9 total degrees).

A surprise in the data was the low numbers of Bachelor's degrees in the field of education: only seven degrees - representing a mere 5\% of all degrees earned - were earned in the field of Education or a closely related discipline (e.g., Exercise and Health Science). This finding could be erroneous given the self-reporting of CVs and degree types and fields, yet for only 5\% of HEAFMs to hold Bachelor's degrees in Education was surprising to say the least.

A table listing the Master's degrees of 119 Higher Education Administration faculty members is listed below. 
Table 2

Master's Degrees Held by Higher Education Administration Faculty Members $(n=119)$

\begin{tabular}{|c|c|c|}
\hline College* & \# of Degrees & Degree, (\#) Earned \\
\hline Business & 5 & Administrative Sciences (1), Business Administration (1), Finance (1), Global Management (1), Systems Analysis (1) \\
\hline Communication & 13 & $\begin{array}{l}\text { Communication Planning and Strategy (1), Industrial Relations Research (1), Policy Studies (1), Political Science (3), } \\
\text { Public Administration (3), Public Affairs (1), Public Policy (2), Social Policy (1) }\end{array}$ \\
\hline
\end{tabular}

Administration, Planning, and Social Policy (3), Comparative International Education (1), Counseling (1), Counseling and Personnel Services (1), Counseling Psychology (1), Education (10), Educational Administration (1), Educational Leadership (1), Educational Research (1), Health and Physical Education (1), Higher Education (40), International

\begin{tabular}{lll} 
Education & 66 & $\begin{array}{l}\text { Education Development (2), International Education Policy (1), Mental Health Counseling (1), Social Studies } \\
\text { Education (1) }\end{array}$ \\
\hline
\end{tabular}

\begin{tabular}{lll}
\hline Education & 66 & Education (1) \\
Engineering & 2 & Engineering (1), Metallurgic Engineering (1) \\
\hline
\end{tabular}

American Culture (1), Anthropology (1), Clinical and Community Psychology (1), Economics (8), English (1), English Literature (1), History (3), International Political Economy (1), Labor Economics (1), Military Art and

\begin{tabular}{lccc} 
Liberal Arts & 36 & $\begin{array}{l}\text { Operational Science (1), Organizational Psychology (1), Psychology (3), Religion (1), Romance Linguistics (1), } \\
\text { Social Psychology (2), Sociology (5), Spanish Linguistics (1), Sport Psychology (1), TESOL (1) }\end{array}$ \\
\hline Natural Sciences & 2 & Human Development and Relations (1), Mathematics (1) \\
\hline Total & 124 & 3 Most Common: Higher Education (40), Education (10), Economics (8) \\
\hline$*$ no degrees from the equivalent disciplines of Architecture, Fine Arts, Geosciences, Nursing, Pharmacy, or Social Work.
\end{tabular}


Similar to Bachelor's degree distribution, a large portion of HEAFMs hold Master's degrees in a Liberal Arts field (36 degrees), but the field of Education (66 degrees or 53\% of all Master's degrees held) was much better represented than for Bachelor degree attainment. The most common Master's degree was in Higher Education (40), followed by an Education degree (10), and an Economics degree (8).

Also similar to Bachelor's degrees, the fields of Architecture, Geosciences, Nursing, Pharmacy, and Social Work produced zero Master's degrees held by HEAFMs. The field of Fine Arts also produced zero degrees, which was surprising, considering that five Bachelor's degrees are held in this field by HEAFMS. However, HEAFMs hold similar numbers of Communication (13), Business (5), and Engineering (2) Master's degrees as they do Bachelor's degrees, possibility speaking to a more streamlined nature of Bachelor's-to-Master's degree programs in these fields.

The data also reveal that of 124 total Master's degrees, only 40 are held in the field of Higher Education. This represents only $32 \%$ of the total Master's degrees earned, while the other $68 \%$ hold a Master's degree in a field or subfield outside of Higher Education. However, degrees in fields such as Administration, Planning, and Social Policy (3) or the subfields of Education (10) and Sociology (5) could be closely related to the field of Higher Education: this uncertainty represents a limitation of the findings. Furthermore, it is unclear how many Communication degrees (13) were closely related to the field of Higher Education, as many Public Policy related degrees could have included Higher Education coursework as partial fulfillments for the degree: again, this uncertainty represents a limitation of the findings.

Idiosyncratic in the data were degrees in fields seemingly unrelated to the field of Higher Education, possibly constituting an alternative program of study or a career change by the degree holder. For instance, a few HEAFMs hold unique Master's degrees in niche fields such as Military Art and Operational Science, Romance Linguistics, and Metallurgic Engineering.

\section{Discussion and Implications}

In short, the findings of this study were fascinating, their implications more so.

To begin, in terms of undergraduate preparation, the field of higher education administration is remarkably diverse. The general public, the audience Gasman addressed in her opinion, would be undoubtedly surprised to learn that only $5 \%$ of higher education administration faculty members earned their Bachelor's degree in the field of Education or a closely related subfield. For comparison's sake, imagine if only 5\% of Fortune 500 CEOs held Bachelor's degrees in Business. Operating in the arena of Higher Education normalizes many experiences known only by its professoriate (e.g., producing reflexive, recursive research about one's employer). However, these types of normative idiosyncrasies must be shared with the general public so it can better understand the incredibly demanding, yet rewarding field of Higher Education and its demonstrated academic diversity. Furthermore, this degree of diversification should be shared with three other groups of educational stakeholders: academic counselors, career counselors, and students of color.

First, all educational stakeholders invested in the academic and career success of students of colorincluding the students themselves - need to be aware of the alternative academic and career paths taken by higher education administration faculty members. For instance, a few HEAFMs hold Bachelor's degrees seemingly incompatible with their field - such as Ceramic Engineering, Medical Microbiology, and Romance Languages-yet these individuals represent a few of the brightest scholars the field of Higher Education has to offer. As a result, students of color must be counseled to understand that a Bachelor's degree does not necessarily predict a career path, nor does it limit the fields one can pursue in graduate school and beyond. Especially for undecided majors or community college students of color unsure of their Bachelor's degree pathway, academic and career counselors must inform students of color of the possibility of relating their degree or coursework toward a future in Higher Education in the form of a pre-Higher Education course of study (e.g., Psychology, Sociology).

Second, pursuing Higher Education graduate studies or entry-level employment after the Bachelor's degree must be emphasized in fields heavily populated by students of color. For instance, Hispanic/Latino students often major in International Business (22\% of all degrees), Interdisciplinary Studies (19\%), and Industrial and Manufacturing Engineering (17\%) (Center on Education and the Workforce, 2015): if these students do not find employment in these fields upon graduation, career counselors must make the option of Higher Education scholarship and/or entry-level employment a possibility. The same can be said of the Black/African-American 
student undergraduate experience. Black/African-American students often major in Health and Medical Administration (21\% of all degrees), Community Organization (20\%), and Social Work (19\%), all fields seemingly unrelated to Higher Education, yet these students of color should be informed of the possibility of translating these types of degrees into Higher Education scholarship or employment opportunities. As the data show, barely half of all Master's degrees held by HEAFMs fall under the vast umbrella of Education. In order for the Higher Education professoriate to become more racially and ethnically diversified, students of color must be counseled at both the Bachelor's and Master's level to see the field of Higher Education as a possible field of study, even if their degrees are seemingly unrelated to this field.

Third, the inverse of the aforementioned paragraph is true: students of color majoring in fields popular with HEAFMs - such as Psychology, Sociology, Economics, and English — should be informed about the possibility of pursuing Higher Education as field of graduate study and eventual employment as faculty members. Before this study, it was unclear which fields produced the higher education administration professoriate, but understanding that $34 \%$ of these professionals hold Bachelor's degrees in either Psychology, Sociology, Economics, or English, it is imperative that students of color be aware of this viable academic and career path. Furthermore, students of color studying in the Liberal Arts field must be aware of the possibility of Higher Education as a graduate field of study, as $62 \%$ of all Bachelor's degrees held by HEAFMs came from Liberal Arts fields.

Fourth, graduate students of color in all fields outside of Education must be counseled to consider Higher Education as a doctoral field of study. As the data show, only 53\% of all Master's degrees held by HEAFMs came from the Higher Education field or a subfield closely related to Higher Education. In fact, there were nearly as many Master's degrees in Economics (8) as there were general Master's degrees in Education (10) held by these professionals. In short, academic and career counselors at both the Bachelor's and Master's degree level need to counsel students of color to consider pursuing advanced degrees in Higher Education in order to diversify the higher education professoriate.

Finally, education policymakers - after understanding the incredible academic diversity of the Higher Education field - should encourage recruitment, retention, mentoring, and scholarship programs for students of color pursuing careers in the higher education administration professoriate: this includes majority-minority groups such as Hispanic/Latino, Black/African-American students but also underrepresented groups such as Asian/Pacific Islander and American Indian/Alaska Native students of color. In this regard, the field of Higher Education could be an industry leader by catalyzing their own academic diversity to further diversify their field by actively counseling students of color toward pre-Higher Education Bachelor's programs (e.g., Sociology) and/or Higher Education Master's and Doctoral degree programs.

\section{Conclusion}

Educating the academe, at least higher education administration faculty members, requires an incredibly diverse array of academic programs and undergraduate education experiences: this is precisely what makes the field of Higher Education so special and full of promise for students of color.

Hearkening back to Gasman's "We don't want them" sentiment, perhaps it isn't because the Higher Education professoriate doesn't want a diverse faculty: this study proves Higher Education already incredibly academically diverse. Of course, Gasman was specifically speaking strictly about racial and ethnic diversity, but the point remains: perhaps higher education — and other academic fields - do not adequately recruit and retain students of color in fields which could lead to scholarship and employment in higher education. As a field that represents such an academic diversity - perhaps idiosyncratic by design and necessity — higher education professionals at all levels must actively recruit students of color from a variety of undergraduate and graduate backgrounds into the field. To hearken back to Gasman, this call to action must be heard by elite IHEs. These institutions specifically have the human and capital resources necessary to transform academic diversity into racial and ethnic diversity in higher education administration faculties across the country: now, elite IHEs and their higher education departments must connect with multiple levels of academic study - Bachelor's through Master's and Doctoral - and their educational stakeholders to make clear the fact that students of color can possibly break through the glass ceiling and earn faculty positions at major institutions by focusing their studies on Higher Education earlier in their academic careers. Or, inversely, students of color must be aware that the field of Higher Education does not require a mandated, specific course of study: its academic diversity is precisely what can make the field just as racially and ethnically diverse. 
The future research possibilities born from this study are plentiful. First, a follow-up study could be conducted that includes a larger sample taking into account the academic backgrounds of higher education administration faculties from institutions outside of the top ten. Furthermore, the degree-granting institution of each degree-Bachelor's through Doctoral - should be examined, as it is entirely conceivable that the field of Higher Education prefers degrees from elite IHEs. Also, the pre-faculty experiences of current higher education administration faculty members require investigation, as it is likely that an overwhelming percentage of current higher education administration faculty members did not begin their professional career in Higher Education, evidenced by their Bachelor's and Master's degree attainment. This type of pre-faculty diversity could inform the recruitment and retention of other forms of diversity, including racial and ethnic diversity.

Ultimately, if Higher Education turns the mirror onto itself and researches Higher Education and its academically diverse faculty, perhaps racial and ethnic diversity will follow suit. Until then and considering people of color, "We don't want them" might be as synonymous with Higher Education as any other field.

\section{References}

[1] Abdul-Raheem, J. (2016). Faculty diversity and tenure in higher education. Journal of Cultural Diversity, 23(2), 53-56.

[2] Carnevale, A. P., Fasules, M. L., Porter, A., \& Landis-Santos, J. (2016, February). African Americans: College majors and earnings. Retrieved from Georgetown University website: https://cew.georgetown.edu/cew-reports/african-american-majors/

[3] Ceglie, R. (2011). Underrepresentation of women of color in the science pipeline: The construction of science identities. Journal of Women and Minorities in Science and Engineering, 17(3), 271-293.

[4] Center on Education and the Workforce. (2015, October). Hispanics: College majors and earnings. Retrieved from Georgetown University website: https://cew.georgetown.edu/cew-reports/hispanicmajors/

[5] Edwards, K. T. (2015). Perceptions of power and faith among black and women faculty: Re-thinking institutional diversity. Innovative Higher Education, 40(3), 263-278. Retrieved from http://link.springer.com.ezproxy.lib.utexas.edu/article/10.1007\%2Fs10755-014-9312-5

[6] Finkelstein, M. J., Conley, V. M., \& Schuster, J. H. (2016). Taking the measure of faculty diversity. Advancing Higher Education, (April), 1-18. Retrieved from https://www.tiaainstitute.org/public/pdf/taking_the_measure_of_faculty_diversity.pdf

[7] Gasman, M. (2016, September 26). An ivy league professor on why colleges don't hire more faculty of color: "We don't want them". Retrieved from The Washington Post website: https://www.washingtonpost.com/news/grade-point/wp/2016/09/26/an-ivy-league-professor-on-whycolleges-dont-hire-more-faculty-of-color-we-dont-want-them/

[8] Hurtado, S., Newman, C. B., Tran, M. C., \& Chang, M. J. (2010). Improving the rate of success for underrepresented racial minorities in STEM fields: Insights from a national project. New Directions for Institutional Research, 2010(148), 5-15.

[9] Museus, S. D., Palmer, R. T., Davis, R. J., \& Maramba, D. C. (2011). Racial and ethnic minority students' success in STEM education. ASHE Higher Education Report, 36(6), 1-140.

[10] National Center for Education Statistics. (2016). Bachelor's degrees conferred by postsecondary institutions, by field of study: Selected years, 1970-71 through 2013-14. Retrieved from National Center for Education Statistics website: http://nces.ed.gov/programs/digest/d15/tables/dt15_322.10.asp?current=yes

[11] Okahana, H., Feaster, K., \& Allum, J. (2016). Graduate enrollment and degrees: 2005 to 2015.

Retrieved from Council of Graduate Schools website: http://cgsnet.org/ckfinder/userfiles/files/Graduate\%20Enrollment\%20\%20Degrees\%20Fall\%202015\%20Fina 1.pdf

[12] Pentyala, S., Dilger, J., \& Rebecchi, M. (2016). Minority students and STEM careers: Will mentoring help? Journal of Health Education Research \& Development, 4(2), 1-5. http://dx.doi.org/10.4172/23805439.1000175

[13] Sowell, R., Allum, J., \& Okahana, H. (2015). Doctoral initiative on minority attrition and completion. Retrieved from Council of Graduate Schools website: http://cgsnet.org/ckfinder/userfiles/files/DIMAC_2015_final_report_PR.pdf

[14] The University of Texas at Austin. (2016). Academics. Retrieved from The University of Texas at Austin website: http://admissions.utexas.edu/explore/academics

[15] U.S. News \& World Report. (2016). Best higher education administration programs: Top education schools. Retrieved from US News \& World Report website: http://grad-schools.usnews.rankingsandreviews.com/bestgraduate-schools/top-education-schools/higher-education-administration-rankings?int=a11808\&int=a06908 